\title{
Las voces indígenas ante la crisis de la monarquía hispana
}

\section{Indigenous Voices Facing the Crisis of the Spanish Monarchy}

\author{
Margarita MENEGUS BORNEMANN \\ https://orcid.org/0000-0002-7944-6835 \\ Universidad Nacional Autónoma de México (México) \\ Instituto de Investigaciones sobre la Universidad y la Educación \\ menegusmargarita@gmail.com
}

\section{Resumen}

El objetivo de este artículo es contrastar la visión de los indios de los diversos estamentos de la sociedad novohispana en el siglo xviı y los primeros años del xıx. Asimismo, se analizan diversas voces indígenas que se manifestaron contra el mal gobierno y los funcionarios de la corona española a partir de 1750, apelando al rey para que corrigiera los abusos y administrara la justicia en América a favor de los naturales. Finalmente, se describe la reacción de los cabildos indígenas ante el levantamiento de Miguel Hidalgo y cómo las Cortes de Cádiz enfrentaron el mismo suceso.

Palabras clave: indios letrados, cabildo indígena, levantamiento de Hidalgo, Cortes de Cádiz

\begin{abstract}
The purpose of this paper is to compare the views of diverse New Spain castes (estamentos) on the indigenous people in the 18th and early 19th centuries. It also analyzes various indigenous voices against the bad government and officials of the Spanish Crown, while appealing to the king to correct the abuses against the natives and impart justice for them from 1750 onwards. Finally, we describe, on the one hand, how the indigenous councils (cabildos indígenas) reacted to the Hidalgo uprising, and how the Cortes of Cádiz, on the other, contested the same event.
\end{abstract}

Keywords: Literate Natives, Indigenous Councils, Uprising of Hidalgo, Courts of Cadiz 
Los Borbón y los indios

En el siglo XVIII, a raíz del cambio en la casa reinante en España, aparecieron políticas nuevas con respecto al indio. Por un lado, existen intentos, aunque tibios, por asimilar al indio, o lo que es lo mismo eliminar las dos repúblicas para constituir una sola. Esta política de integración o de asimilación se reflejó en los esfuerzos por castellanizar a los naturales, o a través de la fundación de escuelas de primeras letras. La castellanización tenía por objetivo acabar con la política inicialmente fomentada por las primeras tres órdenes mendicantes que se dieron a la tarea de evangelizar a los naturales en su propio idioma. Pero este mismo propósito se puede observar en el intento por parte de la Corona por eliminar el tributo y sujetar a los indios solamente al pago de la alcabala. Finalmente, en esta corriente de pensamiento llamada ilustrada vemos también que las palabras vertidas por el obispo Manuel Abad y Queipo en su famosa Representación, cuando hablaba del indio y sus bienes, fueron recogidas por el pensamiento liberal después de la independencia. Abad y Queipo consideró necesario abolir el régimen de las dos repúblicas y acabar con la propiedad comunal fomentando la propiedad privada. Y lo dijo así:

El color, la ignorancia, la miseria de los indios los colocan a una distancia infinita de un español. El favor de las leyes en esta parte les aprovecha poco y en todas las demás les daña mucho. Circunscriptos en el círculo que forma un radio de seiscientas varas que señala la ley a sus pueblos, no tienen propiedad individual.

Y más adelante señalaba:

Separados por la ley de la cohabitación y enlace en las otras castas, se hallan privados de las luces y auxilios que debían recibir por la comunicación y trato con ellas y con las demás gentes. Aislados por su idioma y por su gobierno el más inútil y tirano, se perpetúan en su costumbres, usos y supersticiones groseras, que procuran mantener misteriosamente ocho a diez indios viejos que viven ociosos a expensas del sudor de los otros, dominándolos con el más puro despotismo. ${ }^{1}$

Se refiere sin duda a los caciques. Pero esta política de asimilación o integración fue decididamente combatida por algunos criollos, quienes

${ }^{1}$ José María Luis Mora, Obras Sueltas (México: Porrúa, 1963), 205. 
veían en el monarca, particularmente de Carlos III, la intención de favorecer a los indios, produciéndoles un conflicto con sus propios intereses. Uno de los mayores exponentes de esta posición ideológica fue el arzobispo de México, Manuel José Rubio y Salinas, quien tenía una idea muy negativa acerca de los indígenas americanos. En una carta al rey escrita en 1755 decía las siguientes atrocidades:

No hallo a que atribuir esta desgracia más que a los ocultos e inescrutables juicios de Dios, que assí como pensionó a todo el género humano a tantas calamidades, y miserias por el pecado del primer hombre, assí también por los de otros castigó a su posteridad y descendencia perpetuamente, condenándola a la servidumbre, a la esclavitud, y a la miseria, y que lo mismo pudo suceder con los miserables Yndios, porque solo assí se puede componer tanta resistencia a los arbitrios de la prudencia humana, y a los más vigorosos esfuerzos, que se havran hecho jamás por civilizar una nación, y que no han sido tantos los que se hicieron con tan féliz suceso $[\ldots]{ }^{2}$

Es decir, los indígenas eran una raza condenada a la servidumbre. El discurso de Rubio y Salinas nos recuerda los argumentos aristotélicos expuestos siglos antes por Sepúlveda. Por otra parte, tampoco le merecía mejor opinión al arzobispo ilustrado la nobleza indígena:

Hay en las inmediaciones desta ciudad de familiares de indios, que desde el principio se intimaron mucho con los españoles, y de ellos tomaron los ilustres apellidos, que llevaron en memoria de sus protectores aquellos reyes, governadores o cavalleros que procuraron adelantarlos, y por una especie de galantería les permitieron llevar hasta en sus escudos de armas, pero todas esta familias viven pobres, y obscuramente, sin que de ellas se pueda sacar nada que sea útil al servicio del estado porque los bienes, que fueron dote de los cacicazgos se han enagenado, y solamente ha quedado el nombre y la exempción de no tributar. ${ }^{3}$

Compartía con el rey sus dudas sobre las ventajas resultantes de educar a los naturales de la tierra.

Qué se havía de dar a los jóvenes, educados, cuando llegasen a ser hombres; los que no tuviesen vocación para el estado eclesiástico se verían precisados a

\footnotetext{
2 Archivo General de Indias (en adelante AGI), México, v. 1937.

${ }^{3}$ AGI, México, v. 1937.
} 
salir del colegio para gañanes o jornaleros o a ejercitar las artes mechánicas o a vivir ociosos, y vagavundos; porque no teniendo patrimonio, tierras, casas, mayorazgos, ni rentas que heredar de sus padres, era preciso, que de alguno de los arbitrios propuestos viviesen en las Yndias, no hai ejército, ni armadas marítimas, ni órdenes militares $[\ldots] .{ }^{4}$

\section{Y añadía:}

Los empleos y cargos de administración de justicia, y real hacienda, son poquísimos, en comparación de lo que son estos dominios en su población y grandeza, a estos son acreedores todos los vasallos de España y los españoles de estos dominios que apenas los alcanzan y con dificultad pueden conseguirlos [...]. ${ }^{5}$

No obstante estas consideraciones particulares del ignorante y perverso arzobispo, la realidad es que desde 1697 una real cédula mandaba puntualmente a los arzobispos y obispos que ordenasen sacerdotes a los indios y además aceptasen a las mestizas que quisieran ser religiosas, argumentando con base en la propia Recopilación de leyes de los reinos de las Indias, ley siete, título siete del libro primero. Además, añadía que los naturales como vasallos libres del rey pudieran ascender a los cargos eclesiásticos o seculares, gubernativos, políticos y de guerra. ${ }^{6}$

Claramente, en su discurso, el arzobispo es motivado por la amenaza que representaban los sacerdotes indígenas al ocupar curatos en lugar de criollos o peninsulares. ${ }^{7}$ Por lo cual, concluye el arzobispo que no hay ninguna razón para educar a los indígenas y mucho menos fomentar la formación de un clero indígena.

También en este periodo surgío la obra de Francisco Xavier Clavijero, quien junto con otros expositores de la época reivindicó las glorias de la civilización indígena anterior a la Conquista, y consideró que el indio actual no guardaba ninguna semejanza con aquél. Esta posición historiográfica

${ }^{4}$ AGI, México, v. 1937.

5 AGI, México, v. 1937.

6 "Real Cédula sobre dar honras y cargos a los indios de América, 26 de marzo de 1697", Archivo General de la Nación, Reales Cédulas, v. 27, exp. 11. Y para ver cuántos indígenas se graduaron de la Real Universidad: Margarita Menegus y Rodolfo Aguirre, Los indios, el sacerdocio y la Universidad en Nueva España. Siglos XVI-XVIII (México: Universidad Nacional Autónoma de México/Plaza y Valdés, 2006).

${ }^{7}$ Citado en: William B. Taylor, Ministros de lo sagrado, 2 v., (México: El Colegio de Michoacán/Secretaria de Gobernación/El Colegio de México, 1999). 
trascendería al siglo XIX y se revindicaría igualmente a ese indio ideal, o idealizado, pero ya extinto. Clavijero, en su obra Historia antigua de México, sentaría las bases de la historia patria desarrollada en el siglo XIX. Este jesuita reveló con claridad las motivaciones que lo llevaron a escribir.

La historia antigua de México que he emprendido para evitar la fastidiosa y reprensible ociosidad a que me hallo condenado, para servir del mejor modo posible a mi patria, para restituir a su esplendor la verdad ofuscada por una turba increíble de escritores modernos de la América, me ha sido no menos fatigosa y difícil que dispendiosa. ${ }^{8}$

Se refirió a escritores como William Robertson, Cornelius de Paw y Guillaume-Thomas Raynal, entre otros, quienes forjaron con sus trabajos la llamada leyenda negra de la conquista española. ${ }^{9}$

También veremos cómo el siglo XIX recogió otra inquietud inicialmente planteada por Lorenzo Boturini y por el mismo Clavijero, quienes deseaban rescatar las antigüedades mexicanas, es decir, sus códices y documentos más antiguos. El siglo xıx llevaría esta inquietud a su máxima expresión, fundando museos o lo que los franceses llamaron curiosités, o sea, esas cosas curiosas de los pueblos antiguos o las extravagancias de los pueblos no europeos.

Los elementos que caracterizan la relación de la nueva nación mexicana del siglo xIX frente al indio estaban ya presentes en el siglo XVIII. La idea de asimilar u homogenizar a la población a través del principio de la igualdad, por un lado, y por otro, el desprecio al indio vivo y la exaltación del indio muerto.

El indio visto por el indio

A través de esta sucesión de pinceladas he descrito el devenir del indio a lo largo de los siglos a los ojos de otros. A continuación, debemos también incluir la voz del indio sobre sí mismo. En la segunda mitad del siglo XVIII,

${ }^{8}$ La obra de Francisco Javier Clavijero tiene varias ediciones, para este análisis, véase: Historia antigua de México (México: Imprenta de Juan R. Navarro, 1853).

${ }^{9}$ Por ejemplo, véase Juan Nuix Perpiña, Reflexiones imparciales sobre la humanidad de los españoles en las indias contra los pretendidos filósofos y políticos. Para ilustrar las historias de MM Raynal y Robertson (Madrid: Impresor de Cámara de S. M. con privilegio, 1782). 
los indios alzaron la voz y denunciaron, por un lado, las atrocidades cometidas contra su nación; por otro lado, defendieron a su nación con una clara conciencia de nación.

Este fue el caso de don Julián Cirilo de Galicia y Castilla Aquiahualcateuhtle, indio noble de Tlaxcala, quien buscó con ahínco, a lo largo de su vida, fundar un colegio para la formación de un clero indígena. ${ }^{10}$ El colegio llamado San Carlos Borromeo tenía el propósito de que:

[...] recogiéndose los clérigos y sacerdotes indios, que quisiesen vivir a imitación de San Phelipe Neri, San Carlos Borromeo o del Salvador, pudiendo ejercitarse en todo género de virtudes y letras, y educados, enseñar a los Indios en su Juventud, instruyéndolos en los dogmas sagrados y políticos para que repartiéndose por los Pueblos de sus Paysanos y compatriotas, les dirigiesen al conocimiento. ${ }^{11}$

Claramente, don Julián Cirilo expresó la noción de una nación indígena, nos habla de paisanos y de compatriotas. Además, consideraba que los curas criollos no cumplían satisfactoriamente con su función por las siguientes razones:

En aquellas dilatadas regiones hay indefinida diversidad de lenguas y para la inteligencia de cada una, no hay las correspondientes cathedras, resultando de aquí, que los indios que no están instruidos en la lengua común del País o en la castellana quedan sin doctrina y embueltos en mil errores e idolatrías, no por causa que, por qué no tienen ministro que se las den a entender y los desengañan. ${ }^{12}$

${ }^{10}$ Véase "Los naturales de Tepeaca por todos los indios de Nueva España al rey. 8 de diciembre 1782”, AGI, México, v. 1811; Luisa Zahino Peñafort, "La cuestión indígena en el IV Concilio Provincial Mexicano", Relaciones. Estudios de Historia y Sociedad, Zamora, v. xII, n. 5 (invierno 1990): 5-31; y Margarita Menegus, "Los estudiantes indígenas del obispado de Puebla en la Real Universidad”, Dimensión Antropológica, v. 65, n. 22 (2015): 221-242.

${ }^{11}$ Margarita Menegus, "El Colegio de san Carlos Borromeo: un proyecto para la creación de un clero indígena en el siglo Xviı", en Educación, universidad y sociedad: el vínculo crítico, coord. de Hugo Casanova y Claudio Lozano (México: Universidad Nacional Autónoma de México, Instituto de Investigaciones sobre la Universidad y la Educación/Universidad de Barcelona, 2007), 208.

12 Margarita Menegus, ed., La formación de un clero indígena. El proyecto de don Julián Cirilo de Galicia y Castilla Aquihualeteuhtle para un colegio-seminario, siglo XVIII (México: Cuadernos del Archivo Histórico de la Universidad Nacional Autónoma de México 24, 2013), 11. 
En la Real y Pontificia Universidad de México tan sólo había dos cátedras de lenguas indígenas, náhuatl y otomí, cuando existían decenas de lenguas nativas más, por lo cual aquellos criollos educados ahí frecuentemente desconocían otras lenguas autóctonas. Preocupado por sus connaturales, don Julián Cirilo de Galicia y Castilla propuso al rey remediar la falta de cuidado que recibía la educación de los indios por parte de la iglesia secular en manos de criollos y peninsulares, mediante la fundación, en la Villa de Guadalupe, del colegio-seminario de San Carlos Borromeo para la formación de sacerdotes indígenas. ${ }^{13}$

El sacerdote tlaxcalteca fundamentó su petición alegando la fidelidad que siempre habían mostrado los naturales al rey y recordándole al monarca lo mucho con lo cual habían contribuido los indios a engrandecer su real patrimonio.

Porque mérito puede igualarse al de haverse rendido a los señores Reyes de Castilla más de doscientos millones de Almas. ¿Qué dádiva se puede igualar a la que hizieron los Indios a la Corona de España rindiéndole un Nuevo Mundo, cuias dilatadas regiones se extienden en sólo lo descubierto por más de setecientas leguas que las tres partes del orbe antiguo? Ni que don puede ofrecerse al soberano que aún se asemeje a tantos millones de oro, plata, perlas, piedras preciosas y demás efectos con que aquellos Reynos a esta Catholica Corona frecuentemente contribuien. Pues todos estos méritos tienen, señor, los Indios y los hazen presentes a V. M. ${ }^{14}$

El argumento, claro y contundente, apelaba a la conciencia del rey para que fuese recíproco con aquellos que le habían dado tantos millones, fundándoles bajo su patronato un colegio para su bienestar y educación.

Después de muchos años de luchar por la fundación del Colegio de San Carlos Borromeo, y de haber viajado a España para impulsar dicho proyecto, ya cansado, don Cirilo lanzó su última condena diciendo de los españoles: "No buscan otros frutos los españoles, ni por otra causa, dan tantas vueltas a los mares, sean mercaderes que comercien, jueces que goviernen, o también los mismos sacerdotes que evangelizan, que la Plata y el Oro"15

${ }^{13}$ Para un desarrollo de estas cuestiones, puede verse Margarita Menegus y Rodolfo Aguirre, Los indios, el sacerdocio..., 207-216.

${ }^{14}$ Margarita Menegus, ed., La formación de un clero indígena..., 12.

15 AGi México, v. 1937. [Subrayado mío.] 
Sabemos que don Julián Cirilo estaba en contacto con un mestizo cuzqueño de nombre fray Calixto de San José Tupac Inca, quien le escribió a Fernando VI un documento en tono de denuncia profética alegando que no podía haber "una congregación universal de los fieles" ni una iglesia autóctona mientras no se les permitiera a los indios ordenarse y ejercer como clérigos. ${ }^{16}$ Según Jaime Cuadriello, don Julián Cirilo de Galicia y Castilla fungió como depositario de los poderes que le otorgó fray Calixto de Tupac Inca para que le entregase al rey Fernando VI su Representación en defensa del indio.

Si bien en Nueva España había un clero indígena incipiente, en Perú las condiciones eran todavía más restringidas para los naturales de la tierra. Lo importante de la relación entre don Julián Cirilo, indio tlaxcalteca, y el cuzqueño fray Calixto de San José Tupac Inca era su proyecto en común en defensa del indio. ${ }^{17}$ En la obra Planctus indorum christianorum in America peruntina, atribuida parcialmente a fray Calixto, se argumenta a favor de la creación de un sacerdocio indígena en términos muy parecidos a los de don Julián Cirilo. Se abordan también las restricciones impuestas a los indios y a los mestizos para obtener las órdenes sagradas, entrar a una de las religiones y ocupar cargos como dignidades eclesiásticas en el caso del virreinato del Perú. Se queja de la escasez de conversiones y de los abusos del clero criollo. ${ }^{18}$

Al igual que otros indígenas ilustrados de su época, don Julián Cirilo era conocedor de la obra de fray Bartolomé de las Casas, lo había leído y lo invocó numerosas veces para defender a los indios; es decir, las Casas era el ideólogo de los indígenas letrados del siglo xviII. A través de la correspondencia que mantuvo con el rey y con el Consejo de Indias, sabemos de algunas otras lecturas que don Julián Cirilo conocía. En dichas cartas citaba la obra de Juan de Torquemada, Monarquía indiana; al jesuita Joseph de

16 Jaime Cuadriello, Las glorias de la República de Tlaxcala o la conciencia como imagen sublime (México: Universidad Nacional Autónoma de México/Instituto Nacional de Bellas Artes, Museo Nacional de Arte, 2004), 144. También, Margarita Menegus, "Los estudiantes indígenas...”. Fray Calixto de San José Tupac Inca se ordenó de franciscano. Era mestizo. Viajó a España en 1749 para hacer una defensa del indio. Escribió Exclamación reinvindicacionista. Fue encarcelado por el virrey Superunda, acusándolo de haberse aliado con Atahaualpa. Murió en 1770.

${ }^{17}$ Para mayor información sobre la obra de fray Calixto, véase José María Navarro, Una denuncia profética desde Perú a mediados del siglo XVIII: El Planctus indorum christianorum in America Peruntina (Lima: Pontificia Católica Universidad del Perú, 2001).

${ }_{18}$ Para mayor información, véase el magnífico estudio de José María Navarro, Una denuncia profética... 
Acosta, particularmente su obra de Procuranda indorum salute; y además la obra de Agustín Dávila Padilla, Historia de la fundación de la provincia de Santiago de México de la Orden de los Predicadores, publicada en 1596. Por otra parte, siempre argumentaba citando profusamente la legislación novohispana, con base en la Recopilación de leyes de los reinos de Indias, y lo que ahí estaba mandado y no se cumplía. De igual manera, vale mencionar a Vicente Mora Chimo Cápac, para el caso de Perú, pues fue un importante precursor de este movimiento de letrados indígenas que apelaban a la conciencia del rey para que administrara la justicia entre los naturales. Chimo Cápac estuvo en la corte de Madrid en 1732 como procurador y defensor de indios. Presentó un texto intitulado Manifiesto de los agravios, bexaciones y molestías, que padecen los indios del reyno de Perú. ${ }^{19}$

En ese mismo tenor, el presbítero don Julián Cirilo de Galicia y Castilla presentó al rey Fernando VI un Memorial en 1753 en el que solicitaba la creación de un colegio-seminario destinado a la formación de un clero indígena, como ya hemos referido. Para promoverlo viajó a España entre 1778 y 1790. Debido a la guerra no pudo regresar a Nueva España y falleció en aquellas tierras. En su testamento de 1789 dejó 172 pesos y nueve reales junto con varios libros para que con ello se iniciara la fundación de dicho colegio-seminario. Por desgracia, sólo sabemos que los libros llegaron a Veracruz en 1803; sin embargo, carecemos de una descripción de éstos. En torno al proyecto de don Julián Cirilo se pueden encontrar diversas voces indígenas a favor. Aquí expongo algunos casos en los que la defensa de los indios fue expuesta por indios ilustrados, quienes se basaron tanto en los tratados de las Casas como en la legislación de las Indias.

La carta inicial escrita por don Julián Cirilo está fechada en 1753 y el famoso Memorial escrito por fray Calixto Tupac Inca es de 1749. En su extensa obra titulada Representación verdadera y exclamación rendida y lamentable que toda la nación indiana hace a la Majestad del señor Rey de las Españas... Fernando VI, presentaba la situación de oprobio que vive la nación indiana en el Perú y sugería cómo remediarla. ${ }^{20}$ Al igual que don Julián Cirilo, fray Calixto citaba a las Casas, al inca Garcilaso de la Vega, a Juan de Solorzano y las leyes de Indias. Entre sus peticiones también estaba la

${ }^{19}$ Carlos García Bedoya, La literatura peruana en el periodo de estabilización colonial (Lima: Universidad Nacional Mayor de San Carlos, 1990).

${ }^{20}$ La bibliografía en torno a este personaje es muy amplia, véase: Elena Altuna, "Avatares de una 'Nación Indiana': La representación y exaltación de Fray Calixto Túpak Inca (1750)", América sin Nombre, n. 18 (2013): 23-33. 
ordenación sacerdotal de indios. Evidentemente, el escrito de fray Calixto precede al de don Julián Cirilo en el tiempo, pero sin duda encontramos muchas afinidades entre los dos autores.

Varias voces más se mostraron a favor de la iniciativa de don Julián Cirilo. El bachiller don Andrés Ignacio Escalona y Arias Axayacatzin y Temilo, descendiente de la noble casa de Collancasco, gobernador y vecino de la parcialidad de Santiago Tlatelolco, en un documento extenso apoyó abiertamente la iniciativa de formar un clero indígena; al igual que lo hizo el guardián del convento de San Francisco de aquella parte, Joseph Leyza, en los siguientes términos: ${ }^{21}$

Las extremas necesidades y total desamparo con que crían en estas regiones los hijos y la juventud de los naturales, pues faltos en todo de enseñanza, sólo tienen de racionales lo que les infunde la humana naturaleza, resultando de este tan lastimoso principio hallarse estas pobres gentes, expuestas al vilipendio, pues no instruidas en la vida sociable quedan incapaces de poder ascender al menor puesto, ni tienen la República algún género de mando. ${ }^{22}$

La argumentación de don Andrés Escalona y Arias se apoya también, una y otra vez, en la obra de las Casas, particularmente en La apologética historia sumaria, sobre todo en los pasajes donde critica la encomienda dada a los conquistadores para vigilar el proceso de evangelización de los naturales. ${ }^{23}$

En el siglo XVIII podemos encontrar numerosos ejemplos que reflejan las tensiones entre las dos repúblicas, no obstante los historiadores no los han querido ver. La rivalidad entre indios y criollos parece haber estado más presente en la sociedad novohispana de lo que la historiografía hasta hoy ha recogido.

La rebelión de Tupac Amaru en Perú, así como los diversos movimientos mesiánicos que se dieron en Nueva España, y que buscaban coronar a un monarca indígena, son indicativos de una ruptura entre las dos naciones, cuando, paradójicamente, las autoridades virreinales procuraban una integración. El temor que tenían los criollos a la memoria indígena, a la grandeza de su pasado, se muestra, por ejemplo, en las intenciones del IV Concilio

21 "Solicitud para la reapertura del Colegio de Santiago Tlatelolco, 1728. Documentos firmados por varios caciques”, Boletín del Archivo General de la Nación, t. vi, n. 1 (1935): 23-37.

22 "Solicitud para la reapertura del Colegio de Santiago Tlatelolco, 1728...".

23 "Solicitud para la reapertura del Colegio de Santiago Tlatelolco, 1728...". 
Mexicano al prohibir a los ministros de la iglesia fomentar cualquier cosa que pudiera recordar a los naturales su pasado gentil.

Otro ejemplo lo encontramos en 1790, cuando doña Ana Ventura Gómez, india cacica fundadora del Real Colegio de Indias doncellas de Nuestra Señora de Guadalupe, protestó ante el rey contra la directora de dicha institución por haber permitido la entrada de una española. La carta escrita por doña Ana dice así: "Los caciques y principales de la Nación Indiana..." y continúa diciendo: "Suplicándole rendidamente mande a la Rectora excluya del colegio a dicha española, pues no se nos oculta los grandes y lastimosos quebrantos que de esto sobrevendrá en los futuros tiempos". ${ }^{24}$

Finalmente, sólo para citar otro caso, en 1727 el cacique don Diego Torres, de Tlatelolco, representó a las indias cacicas del convento de Corpus Christi, quienes solicitaron no fuesen admitidas niñas españolas al Colegio. ${ }^{25}$ La identidad tanto indiana como de nación, para el siglo XVIII, era una noción asimilada particularmente por la nobleza indígena. Su rechazo a la población no indígena se hizo extensivo a mestizos y castas. Ésto lo vemos en 1815 cuando el virrey Calleja redactó las nuevas constituciones del antiguo Colegio de San Gregorio, fundado por los jesuitas en el siglo XVI para la educación de los indios. En esa ocasión los indios principales de la ciudad de México se unieron para protestar ante la posibilidad de que fuesen admitidas a dicho colegio personas provenientes de todas las castas, abogando a favor de que se mantuviera como un colegio de indios. Ciertamente, la forma en que utilizó la nobleza indígena el término de nación corresponde a su acepción antigua y no al concepto de nación moderna del siglo xix. No obstante, muestra una clara conciencia de identidad diferenciada de la nación española. ${ }^{26}$

En semejante tono escribieron al rey, en 1782, los gobernadores indígenas de la región de Tepeaca. Iniciaron su argumentación diciendo que los reyes han dado numerosas leyes y reales cédulas que favorecían a los indios.

${ }^{24}$ Margarita Menegus, coord., Saber y poder en México. Siglo XVI al Xx (México: Universidad Nacional Autónoma de México, Centro de Estudios sobre la Universidad, 1997); Josefina Muriel, Las Indias caciques de Corpus Christi (México: Universidad Nacional Autónoma de México, Instituto de Investigaciones Históricas, 2001).

25 Josefina Muriel, Las Indias...

${ }^{26}$ AGI, México, v. 685 
Vuestra Majestad, y el de los demás Señores Reyes que han ocupado el Alto Trono de España las han librado y dirigido a este Reyno, con particulares encargos, a los Excelentísimos Virreyes, Magistrados, E ilustres Prelados, por que la infelicidad con que Dios mantiene en el Mundo a nuestra Nación le tiene acopiado en su contra tan considerable, número de contrarios, que no nos es fácil separarnos, ni experimentarnos, libres de ellos, a causa de que los Mayores en que está depositado el origen, de esta nuestra miseria, es en aquellos Yndividuos, en que Vuestra Majestad tiene puesto la autoridad de su Real Justicia, y los Yllustrísimos Prelados. ${ }^{27}$

Acusaba claramente a los representantes del rey, funcionarios civiles, al igual que los representantes de la Iglesia de:

Estos señores separados enteramente de desempeñar su respectivo encargo, se entregan a la Codicia, a costa y Ruin general de nuestra Nación, que es el blanco de todos sus tiros, y azechanzas, y por esto no nos permiten, perfecta inteligencia en el Ydioma Castellano, y si voluntariamente, alguno de nuestra Nación, se inclina a alcanzar inteligencia, en las Letras, y Ynstrucción, lo que entre nosotros es particular. El que lo logra, de los mismos que tienen Obligación de coayubar a este importante fin, es tratado de Cabildoso, Chismoso, y Capitulero de el Alcalde mayor y Cura de su Doctrina, y para desacreditar en el todo al Yndio que a alcanzado por este medio mexoar de fortuna, hasta con los suyos, lo desacreditan, y se esfuerzan a persuadir no apoyen, ni crean sus Consejos $[\ldots]^{28}$

Una y otra vez denunciaron la malicia de estos funcionarios, su codicia y la falta de respeto que mostraban hacia los naturales de la tierra. Desde los colegios donde estudiaban eran diferenciados de los otros, tratados y nombrados por "macurinos". ${ }^{29}$ Luego pasaron a la defensa del indio cura, comparándolo con los curas españoles. Los indios curas: "Jamás han pensado ni piensa en enriquecer, mantener pompa, ni Rodar forlón, a costa de sus infelices Ovejas, y por eso no es Comerciante, Labrador, Dueño de fincas, ni da motivo a tener pleitos con los Alcaldes Mayores..." 30

La denuncia de los abusos y excesos de los españoles continuaba:

27 “Tepeaca Reyno de México, 8 de diciembre de 1782. El Común de Naturales Yndios. Recibido en el Consejo de Indias el 4 de junio de 1783”, AGI, México, v. 667.

28 "Tepeaca Reyno de México, 8 de diciembre de 1782...".

${ }^{29}$ No he encontrado una definición de la palabra "macurinos".

30 “Tepeaca Reyno de México, 8 de diciembre de 1782...”. 
Es copiosa la infelicidad y miseria de los Yndios que entre todos los Vazallos de Vuestra Majestad que Avitan en sus dilatados Reynos, Provincias, y Yslas, son el ejemplar pues no sabemos haiga otros mas que nosotros. Los que sufrimos el Yugo de la Esclavitud, bajo el nombre, o título de Gañanes de Haciendas, en cuya esclavitud, no solo están perpetuados los hombres, sino también las mugeres, e hijos [...]. ${ }^{31}$

Finalmente, resumiendo esta larga representación al rey, los gobernadores de la provincia de Tepeaca —entre ellos Quecholac, Tecamachalco, Tepexi de la Seda, etcétera - se quejaban de la falta de justicia en los tribunales, donde se acumulaban miles de expedientes sin resolver. Terminaba con las siguientes palabras:

Esta porción de Vasallos Americanos (que solo somos felices, por serlo de Vuestra Majestad Cathólica) Puestos humildes y reverentes, ante el Elevado Trono de Vuestra Majestad y a sus Reales Plantas, por medio de esta Sumisa (y aunque mal explicada) representación Clamoriosa y Sencilla fundada únicamente en nuestro prologando padecer, y en solicitud de alcanzar alivio, Gracia y Clemencia de Vuestra Majestad que es solo el que todo nos lo puede conceder para que esta Nación, que tanto gime y suspira, bajo la tiranía de otros Vasallos de Vuestra Majestad que dominan por toda la dilatación de estas Provincias. ${ }^{32}$

Las diferentes voces muestran que el proyecto de evangelización de los naturales de América era deficiente y manifestan como una solución plausible a estos males la creación de un clero indígena, que además permitiría acotar los abusos del clero criollo o de españoles.

Los cabildos indígenas ante el levantamiento de Hidalgo

La crisis política del imperio se inició en 1808 y adquirió dimensiones preocupantes en 1810 ante el levantamiento del padre Miguel Hidalgo. La crisis de la monarquía ponía en jaque los privilegios de la nobleza en general, y los cabildos indígenas mostraron preocupación ante la insurgencia. Los del Valle de México y de la ciudad de Tlaxcala se manifestaron contra ese

31 “Tepeaca Reyno de México, 8 de diciembre de 1782...”.

32 “Tepeaca Reyno de México, 8 de diciembre de 1782...”. 
movimiento rebelde, pronunciándose a favor de la conservación de la monarquía. El cabildo de la parcialidad de San Juan, integrado en su momento por Dionisio Cano Moctezuma, Francisco Antonio Galicia y Joseph Teodoro Mendoza, entre otros, expresó su lealtad a Fernando VII y calificó el movimiento insurgente como sigue:

El gobernador, alcalde presidente, gobernadores pasados, y toda la república de la parcialidad de S. Juan, han leído la enérgica y juiciosa proclama que V. E. se ha servido dirigir á todos los habitantes de esta N. E. con motivo de que algunos de ellos, olvidados de los sagrados juramentos que los ligan, y de sus verdaderos intereses, han levantado el estandarte de la rebelión, y abierto el camino al pillage, á la devastación y á la ruina total de este preciosísimo reyno. ${ }^{33}$

Y añadieron: "Nosotros que comprendemos nuestra parcialidad, entendemos muy bien que Fernando VII y sus sucesores de la antigua casa Borbón, son los únicos dueños de este reyno". ${ }^{34}$

El 5 de octubre 1810 la parcialidad de Tecpan de Santiago manifestó al virrey su patriotismo y entusiasmo por la causa del rey diciendo:

Exmo. Sr., Hemos leído con gran satisfacción el oficio que dirigió a V. E. la parcialidad de San Juan, y movidos por los mismos sentimientos de religión, lealtad y patriotismo que aquellos [...] En efecto, estamos íntimamente persuadidos de que los sagrados y estrechos vínculos que nos unen con la madre España, no debe cortarse mientras exista un sólo palmo de tierra española, libre de la dominación tiránica. Hemos jurado a nuestro amado soberano el Sr. D. Fernando VII, á su augusta casa, y como representantes de esta legítima potestad, al Consejo supremo de Regencia: a este, pues, solo obedeceremos, y aquel reynará siempre en nuestros corazones..$^{35}$

Las autoridades y voluntarios de Nopalucan, el 8 de octubre de 1810, ofrecieron al virrey sus servicios para sostener al gobierno, expresaron las siguientes palabras:

${ }^{33}$ Juan E. Hernández y Davalos, Colección de documentos para la historia de la guerra de Independencia de México de 1808-1821, v. 2 (México: José María Sandoval, 1878), 115-116.

${ }^{34}$ Juan E. Hernández y Davalos, Colección de documentos..., 115-116.

35 Juan E. Hernández y Davalos, Colección de documentos..., 142. 
Exmo. Sr. Vuestro teniente de justicia del partido de Nopalucan, en voy y en nombre de las repúblicas de naturales de aquella cabecera y sus dos pueblos anexos, con el mas sumiso respeto de mi veneración digo: que ha llegado á mi noticia la desagradable de la sublevación de algunos pueblos de la Tierradentro, y aunque creo que las superiores fuerzas de V. E. domarán bien presto la cerviz de los rebeldes; sin embargo, yo y todos los patriótas de este distrito, ofrecemos todos nuestros arbitrios, y deseamos con impaciencia sacrificar nuestras vidas en obsequio a nuestra religión Santa de nuestro monarca el Sr. D. Fernando VII y nuestra patria: estando dispuestos para quanto V. E. nos consideré útiles [...]. ${ }^{36}$

Lo mismo hicieron las parcialidades de Santiago Tlatelolco, Huejotzingo, Xochimilco y Chalco. En el caso de esta última así lo expresó:

decimos que habiendo llegado a nuestros oídos el grito tumultuario que dieron tres desnaturalizados españoles americanos, en los pueblos de Dolores, San Miguel el grande y Celaya, inmediatamente se enardecieron nuestros ánimos en su contra, por que de luego a luego conocimos que semejantes pérfidos procederes, aunque acompañados de halagüeñas esperanzas, sólo se dirigían a apartarnos de la religión santa que profesamos y de la obediencia que debemos tener y hemos jurado a nuestro augusto, católico y deseado rey y Sr. D. Fernando VII de Borbón y al supremo Consejo y Regencia, que en nombre de este mismo nuestro adorado monarca, gobierna aquellos y estos dominios, y por lo mismo inmediatamente detestamos sus aborrecibles máximas, y juramos todos morir antes que adoptarlas. ${ }^{37}$

Los cuatro señores de Tlaxcala externaron vehementemente su rechazo a Hidalgo. Los caciques y el ayuntamiento de Tlaxcala se manifestaron contra la insurrección promovida por el señor Hidalgo, diciendo el 20 de octubre de 1810:

El apostata Hidalgo y los infieles y criminosos, Allende, Aldama, Abasolo y demás sequaces, son los que tratan por medio de sus principios impíos, máximas escandalosas y seductivas, desterrar la paz y quietud que gozaba este vasto imperio, valiéndose para tan depravado intento de la seducción y palabras halagüeñas con que piensan engañar la credulidad de nuestros hermanos los indios, para que estos les sirvan a sus iniquos fines. ${ }^{38}$

\footnotetext{
${ }^{36}$ Juan E. Hernández y Davalos, Colección de documentos..., 154-155.

37 Juan E. Hernández y Davalos, Colección de documentos..., 125.

38 Juan E. Hernández y Davalos, Colección de documentos..., 177.
} 
Firmaban entre muchos otros, don Juan Faustino Mazihcatzin, descendiente de unos de los cuatro señores o linajes de Tlaxcala, con sede en la cabecera de Ocotelulco.

El deseo de la nobleza indígena de seguir fiel a la monarquía se comprende en buena parte como defensa de sus propios privilegios dentro del orden monárquico.

Los indios y los insurgentes en el imaginario

de las Cortes de Cádiz

El estudio clásico de Charles Berry demuestra cómo incluso en lo tocante a la elite criolla, los diputados novohispanos eran poco representativos de la sociedad en su conjunto. Durante el periodo de 1810 a 1813, un cuarto de los diputados no asistió a las Cortes y fueron suplidos por seis delegados que residían en España. Por otra parte, las elecciones realizadas conforme al decreto del 14 de febrero de 1810 excluyeron por completo a la población indígena, con lo cual su república no estuvo formalmente representada. Es verdad que en las Cortes se percataron de esta omisión y decretaron el 20 de agosto de ese mismo año que los indios, así como los hijos de españoles e indios - los mestizos-, tenían derecho a elegir a sus representantes. Sin embargo, dicho decreto advertía que, a fin de no entorpecer el procedimiento de las Cortes, los diputados previamente electos permanecerían como tales. En todo caso se realizarían elecciones extraordinarias para que los indios eligiesen a sus representantes o defensores. Elecciones que nunca se verificaron..$^{39}$ A pesar de semejantes irregularidades hubo un diputado indígena, delegado del Perú, Dionisio Inca Yupanqui. El Inca fue educado y criado en España y al momento de integrarse las Cortes residía en la península ibérica. A pesar de su linaje y nobleza, se ocupó en varias ocasiones de la defensa de los indios y de sus intereses corporativos. ${ }^{40}$ Aquella asamblea con una representación sesgada intentaría comprender el levantamiento de Hidalgo, apoyado por indios y castas.

A raíz del movimiento de Hidalgo, los miembros de las Cortes buscaron informarse de los problemas que aquejaban a Nueva España, enviando a Juan

${ }^{39}$ Jorge I. Domínguez, Insurrection or Loyalty. The breakdown of the Spanish American Empire (Cambridge: Harvard University Press, 1980), 183.

${ }^{40}$ María Teresa Berruezo, La participación americana en las Cortes de Cádiz (1810-1814) (Madrid: Centro de Estudios Constitucionales, 1976). 
Antonio Yandiola, archivero de la Secretaría de Hacienda, para que les remitiera su opinión sobre las causas de la insurrección. Yandiola escribió su informe el primero de enero de 1811, en él exponía los motivos que provocaron el levantamiento de Hidalgo y hacía sugerencias para sofocar la rebelión. ${ }^{41}$

En su opinión, el origen de todos los males de Nueva España estaba en el mal gobierno y afirmaba que, después de tres siglos de gobierno hispano, "el pueblo que comprendía a los indios, castas y demás habitantes, vinieron a ser más esclavos que en tiempos de Moctezuma, entonces por su estado salvaje obedecían a su señor, después han sido esclavos de los más viles esclavos, últimos hijos de la monstruosa tiranía". ${ }^{42}$ Para Yandiola, los tiranos eran tanto los virreyes y las justicias locales como el propio clero, entre todos habían dejado al indio en la miseria y la ignorancia. La solución estaba en eliminar el despotismo creando un nuevo código civil, elaborado parcialmente por el propio Yandiola. A su juicio, las medidas por adoptar debían ser drásticas, pues, por una parte, sentía que todos los criollos deseaban la independencia, y por otra, que los indios a causa de su rebeldía habían aprendido que todo cuanto en América había era suyo por derecho inmemorial. Yandiola lo expresó así: "Pero tiene esa insurrección, la terrible circunstancia de haberse hecho general en los indios ciertas máximas que les han usurpado sus seductores de cuanto tienen los demás les pertenecen". ${ }^{43}$

En su opinión, la situación de la Nueva España tenía dos vertientes: una, los deseos de los independistas criollos y, la otra, la reivindicación que comenzaban a hacer los indios de sus tierras, atentando contra la propiedad y los bienes pertenecientes a los españoles. Yandiola propuso las siguientes medidas para pacificar y reformar el gobierno virreinal: el envío inmediato de tropas para reducir con la fuerza al reino a la tranquilidad; la suspensión de las universidades y colegios porque ahí aprendían los americanos "baxas ideas"; que los curatos de indios se proveyesen todos con curas traídos de España; que ningún americano ocupase un cargo en los tribunales; que no se permitiese tener fábricas, y que la figura del virrey fuese eliminada nombrando en su lugar a gobernadores provinciales, etcétera.

La respuesta de la Comisión de Ultramar al informe y a las sugerencias propuestas por Yandiola demuestra con claridad el punto de vista de sus miembros. Esta comisión, formada para entender sobre los asuntos americanos

\footnotetext{
${ }^{41}$ Archivo de las Cortes Madrid (en adelante ACM), Serie General, 22/18.

${ }^{42}$ ACM, Serie General, 22/18.

43 “1811 abril 23. Dictamen de la Comisión de Ultramar", ACM, Serie General, 22/18.
} 
relacionados con los conatos de independencia, las revueltas e insurrecciones suscitadas en aquellas tierras, estaba integrada por peninsulares, hasta donde sabemos, ya que no aparece registrado en el Diario de las sesiones de las Cortes el día de su integración ni la forma de su nombramiento. La Comisión respondió al informe diciendo que: “ [...] ha leído con asombro este papel [...] y en realidad no puede menos que decir que es un acervo de despropósitos mezclados con algunas pocas cosas buenas o razonables que son las extraídas de otros escritos". ${ }^{4}$

La Comisión descalificó rotundamente la opinión y remedios de Yandiola. Un segundo informe fue escrito por José Luyando, fechado el 6 diciembre de 1810 y dirigido a la Comisión de Ultramar. Si bien Luyando no criticó tan agrariamente al gobierno español, puntualizó que la injusticia reinante se debía a la falta de autoridades que administrasen justicia. Afirmaba que en aquel vasto territorio americano sólo existían dos tribunales: el de la Audiencia de México y la de Guadalajara. Por otra parte, las justicias locales, alcaldes, corregidores o subdelegados, efectuaban repartos de mercancías entre los indios, obligándolos a comprarlos a precios extraordinarios, por lo cual no había justicia, pues eran juez y parte. ${ }^{45}$ En otra parte de su Informe, Luyando señalaba que la mayoría de los indios había perdido sus tierras, convirtiéndose en jornaleros de las grandes haciendas. Para remediar la situación, Luyando proponía que se repartiesen tierras incultas, aunque pertenecieran a un mayorazgo y que la iglesia, por su parte, arrendaría las suyas a la población más desprovista del reino. Y en cuanto a los criollos, éstos quedarían satisfechos en tanto las Cortes declararan la igualdad entre peninsulares y novohispanos.

La discusión en las Cortes y los decretos emitidos

sobre los indios y la propiedad

Al finalizar el año de 1810, el diputado Dionisio Inca Yupanqui se pronunció en contra de las vejaciones que padecían los indios y propuso a las Cortes un proyecto de decreto sancionando a quienes abusaran de la población indígena, dirigido a los virreyes y presidentes de las audiencias americanas. Y así lo expresó: "Para que con suma escrupulosidad protejan a los indios,

${ }^{44}$ ACM, Serie General, 22/18.

45 "Informe de 6 de diciembre de 1810 de José Luyando a la Comisión de Ultramar", ACM, Serie General, 22/18. 
y cuiden de que no sean molestados, no aflijidos en sus personas y propiedades, ni se perjudique en manera alguna a su libertad, privilegios, etcétera" ${ }^{46}$ Los diputados españoles fueron amables pero poco receptivos a la propuesta de Dionisio Inca Yupanqui. El diputado Argüelles dijo que "admiraba el celo filantrópico del Sr. Inca; pero soy del dictamen que conforme á Reglamento se deje para otro día la discusión”. El diputado Espiga por su parte opinó: "Me parece muy laudable la proposición... pero la encuentro demasiado general". ${ }^{4}$

No obstante las observaciones anteriores, el 5 de enero de 1811 las Cortes aprobaron en los mismos términos imprecisos la prohibición de que los indios recibieran cualquier tipo de vejación. El 12 de marzo de 1811 se leyó en las Cortes el dictamen de la Comisión de Ultramar sobre las iniciativas que había tomado el virrey Venegas en Nueva España para sofocar la rebelión iniciada en el Bajío.

Al producirse el levantamiento de Hidalgo, el virrey Venegas decretó el reparto de tierras a los indios y la abolición de los tributos. Además, a lo largo de las seis semanas que el padre Hidalgo tardó en acercarse a las afueras de la ciudad de México, hizo una campaña desprestigiando el levantamiento insurgente, buscando asimismo establecer una alianza con los criollos de la ciudad de México y con las repúblicas de indios, como hemos referido páginas atrás. Las Cortes, enteradas de las estrategias tomadas por el virrey Venegas propusieron hacerlas extensivas a toda América. Se decretó, por lo tanto, el reparto de tierras a indios y castas, la abolición del tributo y la supresión del repartimiento forzoso de mercancías. Sin embargo, los diputados de las Cortes aprobaron el reparto de tierras a los indios, pero no a las castas, temiendo que ello abriría la posibilidad de concederles la ciudadanía, con lo cual la delegación americana lograría mayoría absoluta.

Un segundo decreto del 12 de noviembre de 1812, algo más elaborado que el anterior, mandó que se repartieran tierras de las inmediaciones de los pueblos que no fuesen de dominio particular, ni tierras de comunidad, a los indios mayores de 25 años que vivieran fuera de la patria potestad de sus padres. ${ }^{48}$

46 "16 de diciembre de 1810 Discurso del diputado Dionisio Inca Yupanqui sobre las vejaciones que reciben los indios americanos”, Diario de las sesiones de las Cortes Generales y Extraordinarias, t. 1. (Madrid: Impr. J. A. García, 1870), 172.

${ }^{47}$ Diario de las sesiones..., 173-174.

48 "Decreto de 9 de noviembre de 1812". En Colección de decretos y órdenes que han expedido las Cortes Generales y Extraordinarias desde su instalación de 24 de setiembre [sic] de 1810 hasta igual fecha de 1811 [-1823], t. III (Madrid: Imprenta Real, 1820), 161-162. 
Para no alargarme más, los decretos emitidos por las Cortes fueron vagos y contradictorios, particularmente con respecto a la propiedad indígena. En suma, no modificaron en absoluto la estructura agraria ni de propiedad existente.

Curiosamente, la solución propuesta por Abad y Queipo, obispo electo de Valladolid en 1805, de alguna manera tenía en consideración que la crisis novohispana no era una crisis coyuntural, sino estructural del antiguo régimen, por lo cual abogó por la abolición del modelo de las dos repúblicas y pugnó por una sociedad integrada. Con el nuevo modelo habría una mayor equidad, un reparto más justo de la propiedad y el acceso a cualquier empleo o cargo. Finalmente, con base en todo lo dicho anteriormente a través de diversas voces, pareciera que en todos los discursos y apelaciones al rey estaba la injusticia ejercida contra los indios, la falta de justicia, la cual era la base de legitimidad de la figura del rey y de la monarquía. Como ya he mencionado, el deber primordial del monarca era la administración de la justicia. ${ }^{49}$

Conclusión: la permanencia de la monarquía

en el imaginario indio después de la independencia

En conclusión, hemos tratado de explicar cómo algunas reformas borbónicas buscaron integrar más a la república de indios al reino promoviendo la castellanización, incentivando la formación de un clero indígena o estableciendo escuelas de primeras letras. Sin embargo, en buena medida, algunas de estas reformas, específicamente con respecto a la promoción de un clero indígena o a que los indios ocuparan diferentes cargos dentro de la administración virreinal del reino, se enfrentaron a la oposición de los criollos, particularmente del clero secular.

En contraste, desde mediados del siglo XviıI diversas voces indígenas propugnaron por el establecimiento de un clero indígena y por desempeñar cargos dentro de ese orden virreinal como vasallos libres del rey. Además, hemos intentado subrayar la importancia de esas voces indígenas que apelaron a la conciencia y obligación primordial del rey de administrar justicia

${ }^{49}$ Véase para esta discusión Margarita Menegus, "Tributo o alcabala. Los indios y el fisco siglos XVI al XIX. Una encrucijada fiscal” en Las Finanzas Públicas en los siglos XVIII- XIX coord. de Luis Jáuregui y José Antonio Serrano (México: Instituto de Investigaciones Dr. José María Luis Mora, 1998), 110-130. 
en favor de sus vasallos indios, denunciando las atrocidades cometidas por sus representantes en América.

Al momento del levantamiento del cura Hidalgo, las repúblicas de indios levantaron la voz a favor del rey, en contra de los sediciosos. Situación aparentemente paradójica, pero en realidad no lo es, porque, como hemos expresado, los naturales confiaban en el rey para remediar las injusticias a lo largo de la segunda mitad del siglo xviII. Pero, igualmente, los oficiales de república que denunciaron a los insurgentes también tenían claramente presente su deseo de mantener sus privilegios.

Finalmente, dejamos asentado cómo actuaron las Cortes de Cádiz ante el levantamiento de Hidalgo, y cómo la Comisión de Ultramar rechazó los informes, en particular de Yandiola, mostrándose incrédula ante las quejas de mal gobierno.

La conquista cultural fue de suma importancia, no fue abolida con la independencia. Al contrario, se asimiló tanto que en el testamento de 1860 de Martín de Villagómez, cacique de Huajuapan, en la Mixteca baja, éste pidió ser enterrado con el hábito de San Francisco, una práctica por lo demás muy extendida entre la nobleza indígena desde el siglo xVI, y que por lo visto permaneció intacta hasta la segunda mitad del siglo XIX. ${ }^{50}$

O como expresó con toda claridad el cacique de Tequistepec, de la Mixteca oaxaqueña, en 1825: "Quando desde el principio que los españoles ocuparon injustamente este hermoso continente, no derrocaron a los caciques que poblaban la Misteca Baja”. Es decir, a pesar de los atropellos cometidos por los españoles, tuvieron el buen tino de mantener en su sitio a los caciques. "Ahora después de la independencia pretenden desconocer sus derechos antiguos y legítimos". ${ }^{51}$ No obstante esta elocuente defensa de los caciques, la institución del cacicazgo y del mayorazgo fue disuelta a principios de la vida independiente. Ello no significó la pérdida de sus propiedades pero sí un cambio en el régimen de propiedad, en tanto que se prohibió la vinculación de la tierra, y en la forma de heredar también, al suprimirse la figura del primogénito. Los antiguos terrazgueros pertenecientes a un cacicazgo pasaron a ser arrendatarios.

Con todo, el modelo del antiguo régimen basado en derechos diferenciados para nobles, y otros para el común, llevó a que las voces de los indios no fueran una sola.

\footnotetext{
${ }^{50}$ Archivo Histórico Judicial de Oaxaca (en adelante AHJo), Huajuapan, Civil, leg. 37.

${ }^{51}$ AHJo, Huajuapan, Civil, leg. 6.
} 


\section{Fuentes}

\section{Documentales}

Archivo General de Indias (AGI)

Audiencia de México

Archivo General de la Nación (AGN)

Archivo de las Cortes, Madrid (ACM)

Las Cortes de Cádiz, 1512

La Comisión de Ultramar

Archivo Histórico Judicial de Oaxaca (AHJO)

\section{Bibliografía}

Altuna, Elena. “Avatares de una 'Nación Indiana': la representación y exaltación de fray Calixto Túpak Inca (1750)”. América sin Nombre, n. 18 (2013): 23-33.

Berruezo, María Teresa. La participación americana en las Cortes de Cádiz (18101814). Madrid: Centro de Estudios Constitucionales, 1976.

Clavijero, Francisco Javier. Historia antigua de México. México: Imprenta de Juan R. Navarro, 1853.

Colección de decretos y órdenes que han expedido las Cortes Generales y Extraordinarias desde su instalación de 24 de setiembre [sic] de 1810 hasta igual fecha de 1811 [-1823]. T. II. Madrid: Imprenta Real, 1820.

Cuadriello, Jaime. Las glorias de la República de Tlaxcala o la conciencia como imagen sublime. México: Universidad Nacional Autónoma de México/Instituto Nacional de Bellas Artes, Museo Nacional de Arte, 2004.

Diario de las sesiones de las Cortes Generales y Extraordinarias, t. 1. Madrid: Impr. J. A. García, 1870.

Domínguez, Jorge I. Insurrection or Loyalty. The Breakdown of the Spanish American Empire. Cambridge: Harvard University Press, 1980.

García Bedoya, Carlos. La literatura peruana en el periodo de estabilización colonial. Lima: Universidad Nacional Mayor de San Carlos, 1990.

Hernández y Davalos, Juan E. Colección de documentos para la historia de la guerra de Independencia de México de 1808-1821, v. 2. México: José María Sandoval, 1878.

Menegus, Margarita. "Los estudiantes indígenas del obispado de Puebla en la Real Universidad”. Dimensión Antropológica, v. 65, n. 22 (2015): 221-242. 
Menegus, Margarita, ed. La formación de un clero indígena. El proyecto de don Julián Cirilo de Galicia y Castilla Aquihualeteuhtle para un colegio-seminario, siglo XVIII. México: Cuadernos del Archivo Histórico de la Universidad Nacional Autónoma de México 24, 2013.

Menegus, Margarita. "El Colegio de San Carlos Borromeo: un proyecto para la creación de un clero indígena en el siglo xviII". En Educación, universidad y sociedad: el vínculo crítico, coordinación de Hugo Casanova y Claudio Lozano, 207-221. México: Universidad Nacional Autónoma de México, Instituto de Investigaciones sobre la Universidad y la Educación/Universidad de Barcelona, 2007.

Menegus, Margarita. "Tributo o alcabala. Los indios y el fisco siglos XVI al Xıx. Una encrucijada fiscal”. En Las Finanzas Públicas en los siglos XVIII-XIX, coordinación de Luis Jáuregui y José Antonio Serrano, 110-130. México: Instituto de Investigaciones Dr. José María Luis Mora, 1998.

Menegus, Margarita, coord. Saber y poder en México. Siglo XVI al Xx. México: Universidad Nacional Autónoma de México, Centro de Estudios sobre la Universidad, 1997.

Menegus, Margarita y Rodolfo Aguirre, Los indios, el sacerdocio y la Universidad en Nueva España. Siglos XVI-XVIII. México: Universidad Nacional Autónoma de México/Plaza y Valdés, 2006.

Mora, José María Luis. Obras sueltas. México: Porrúa, 1963.

Muriel, Josefina. Las indias caciques de Corpus Christi. 2a. ed. México: Universidad Nacional Autónoma de México, Instituto de Investigaciones Históricas, 2001.

Navarro Pascual, José María. Una denuncia profética desde Perú a mediados del siglo XVIII: el Planctus indorum christianorum in America Peruntina. Lima: Pontificia Católica Universidad del Perú, 2001.

Nuix Perpiña, Juan. Reflexiones imparciales sobre la humanidad de los españoles en las indias contra los pretendidos filósofos y políticos. Para ilustrar las historias de MM. Raynal y Robertson. Madrid: Impresor de Cámara de S. M. con privilegio, 1782 (Edición facsimilar Librerías París-Valencia).

"Solicitud para la reapertura del Colegio de Santiago Tlatelolco, 1728. Documentos firmados por varios caciques”. Boletín del Archivo General de la Nación, t. vi, n. 1 (1935): 23-37.

Taylor, William B. Ministros de lo sagrado. México, 2 v. México: El Colegio de Michoacán/Secretaría de Gobernación/El Colegio de México, 1999.

Zahino Peñafort, Luisa. "La cuestión indígena en el IV Concilio Provincial Mexicano”. Relaciones. Estudios de Historia y Sociedad xıI, n. 5 (invierno 1990): 5-31. 


\section{SOBRE LA AUTORA}

Margarita Menegus Bornermann es investigadora titular del Instituto de Investigaciones sobre la Universidad y la Educación de la UNAM. Sola o en coautoría, entre sus publicaciones destacan La formación de un clero indígena. El proyecto de don Julián Cirilo de Galicia y Castilla Aquihualeteuhtle para un colegio-seminario, siglo XVIII (IISUE-UNAM, 2013), La secularización de las doctrinas de indios. La pugna entre dos iglesias (unAm/Bonilla, 2010), La Mixteca Baja entre la Revolución y la Reforma. Cacicazgo, territorialidad y gobierno, siglos XVIII-XIX (UAM/UABJO, 2009) o, entre otros, Los indios en la historia de México (CIDE/FCE 2006). 